\title{
Introducing LQR-fuzzy for a dynamic multi area LFC-DR model
}

Palakaluri Srividya Devi, R.Vijaya Santhi

Department of Electrical Engineering, Andhra University, India

\begin{tabular}{l}
\hline \hline Article Info \\
\hline Article history: \\
Received May 19, 2018 \\
Revised Oct 8, 2018 \\
Accepted Nov 2, 2018 \\
\hline
\end{tabular}

\section{Keywords:}

Demand response Fuzzy logic control Linear quadratic regulator Load frequency control Padé approximation

\begin{abstract}
It is well known that Load Frequency Control (LFC) model plays a vital role in electric power system design and operation. In the literature, much research works has stated on the advantages and realization of DR (Demand Response), which has proved to be an important part of the future smart grid. In an interconnected power system, if a load demand changes randomly, both frequency and tie line power varies. LFC-DR model is tuned by standard controllers like PI, PD, PID controllers, as they have constant gains. Hence, they are incapable of acquiring desirable dynamic performance for an extensive variety of operating conditions and various load changes. This paper presents the idea of introducing a DR control loop in the traditional Multi area LFC model (called LFC -DR) using LQR- Fuzzy Logic Control. The effect of DR-CDL i.e. (Demand Response Communication Delay Latency) in the design is also considered and is linearized using Padé approximation. Simulation results shows that the addition of DR control loop with proposed controller guarantees stability of the overall closed-loop LFCDR system which effectively improves the system dynamic performance and is superior over a classical controller at different operating scenarios.
\end{abstract}

Copyright $@ 2019$ Institute of Advanced Engineering and Science. All rights reserved.

\section{Corresponding Author: \\ Palakaluri Srividya Devi, Department of Electrical Engineering, Andhra University, Vishakhapatnam Andhra Pradesh India-530003. Email: srividyadevi2001@gmail.com}

\section{INTRODUCTION}

The primary objective of Load Frequency Control (LFC) is to match the demanded power and power that is being generated. Demand response (DR) proposes a variety of fiscal and outfitted benefits for customers of electricity, serving the load entities and operators of grid [1]. DR can be an effective tool in "providing balance between supplies and demand in real-time. Traditionally, such services, known as ancillary services, are provided by utility-owned operating (spinning and no spinning) reserves which are basically flexible capacity generators, available when needed, to maintain secure operation of power systems" [2]. Demand Response (DR) is the alternate in consumption by means of clients in response to charge alerts, incentives, or directions from grid operators in the grid. Although the idea of load following supply existed in advance, DR is rising as a vital feature in smart grid paradigm due to the fact effective DR can be executed best with the help of records conversation generation. DR extensively classified into fee primarily based and incentive based, has been notably studied and analyzed in various aspects. The focus become mainly on top clipping, load shifting and call for manage schemes. For residential load control, thermostatically controlled hundreds (TCL) like heating, ventilating and air conditioner (HVAC) masses are taken into consideration as they motive minimum inconvenience to the users when a generating unit trips or a block of load gets added to the system, the power mismatch is compensated by the primary response of the system, which is to extract kinetic energy from system inertial storage. This causes system frequency 
to decline as speed decreases, and thus power taken by loads decreases. Thus, equilibrium for large systems is often obtained at the resulting new frequency. If the mismatch is large enough to cause the frequency to deviate beyond the governor dead band of generating units, their output will be increased by governor action. Hence load frequency control is also called Automatic Generation control. The objectives of AGC are wellknown from various Authors. Thus, a new input signal Area Control Error (ACE) was defined. Different control strategies have been proposed to balance the supply and demand and to maintain the system frequency for a vertically integrated utility. A mathematical analysis of frequency and tie line power control performance was done in [3]. Quazza in [4] suggested a non-interacting control of frequency and exported power and area autonomy to take care of load variations during transients. A regulator with self-tuning was planned and contrivanced in [5] for the Hungarian power system, in which the power unit was modeled by a dead-time lag. A new paradigm of AGC was proposed in [6], in which a central AGC determines the optimal generation allocation based on incremental cost curvesThus, this frequency control/regulation in Power system has been one of the key control problems for research, ritually termed as Load Frequency Control (LFC). This has been one of the functions of automatic generation control (AGC). The reliability and stability of the power system mainly depends upon frequency deviation from its nominal value. In load frequency control problem frequency and tie-line power exchanges are two variables which should be considered under investigation [7]-[9].

The future strength grid, on the other hand, is foreseen to have excessive penetration of Renewable Energy (RE) electricity generation, which can be fantastically variable. In severe stability situations and absence of enough spinning reserve, load losing, is used because the ultimate lodge. It is worth noting that technology and demand can be similarly applied to the frequency control. Call for Demand response is described as: "changes in electric usage through call for-facet resources from their everyday consumption styles in reaction to changes in the price of electricity over the years, or to incentive payments designed to set off lower energy use at instances of excessive wholesale marketplace costs or when system reliability is jeopardized" by way of federal electricity regulatory commission (FERC) [10], [11]. In such cases, power and energy storage and responsive loads display outstanding promise for balancing technology and call for, as they may help to avoid the usage of the traditional generation following schemes, which may be luxurious and/or environmentally unfriendly. given the limited availability, low performance, and excessive price of huge storage gadgets, actual -time clever responsive load participation, known as Demand Response (DR), has been actively taken into consideration for electricity balancing it could be executed through energetic consumer participation in actual-time to maintain stability among technology and demand with way communication [12]. It is well known that DR will increase gadget reliability and versatility, decreases the value of operation, and enhances machine performance [13]. There are novel procedures to stabilize the frequency in normal and emergency conditions based totally on the new bilateral communicating infrastructure inside a micro grid. Creation of a sophisticated communication infrastructure enhances the techniques for energetic participation of energy customers in call for reaction packages. The inherent tracking potentials of smart grid can overcome the prejudices towards demand aspect assets. As a result, micro-grid is a brand-new paradigm that is described as a cluster of renewable/conventional energy sources and masses that have the salient characteristic of operating in grid related or self-reliant mode [14].

This form of call for can respond autonomously to frequency variant and provide speedy reserve to the machine via equipping them with frequency sensors and appropriate manipulate intelligence. The demand frequency reserve can supply the same provider plus additional blessings like faster reaction speed, doubtlessly decrease charges, well-dispersed in distribution community and pollutants loose in contrast with conventional reserves. simulation results display that, the use of this approach, i.e by introducing call for reaction(DR) control loop to the traditional LFC version (called LFC-DR )the demand facet could make a good sized and dependable contribution to number one frequency reaction whilst retaining the blessings that customers derive from their supply of electrical power. It is indicated that frequency control may be finished via a pre-scheduled situation in place of generation resources; consequently the convenience and priority of the customers are guaranteed. Those models are beneficial in small disturbance studies together with small versions in load and technology, and in controller design [15].inside the beyond a long time, fuzzy logic controllers (FLCS) were efficiently developed for evaluation and control of non-linear structures [16], [17].The fuzzy reasoning method is stimulated via its capability to handle imperfect information; specifically uncertainties in to be had information. The load frequency control with Demand response for single area power system with LQR and intelligent controllers was well documented [18]. The goal of this study is to research Load Frequency Control with Demand Response (LFC-DR) for multi-area at different conditions of operating using the LQR with intelligent control techniques [19], [20]. Power system is a noticeably nonlinear and unsure system. To linearize the device from nonlinearities (communiqué latency related to DR among the load burden aggregator companies (lagcos) and the quit-use customers' devices) Padé approximation is used that's a vital parameter for the system dynamic performance of LFC-DR [21]. 
Taking LQR feature into attention, a strong decentralized manage scheme is designed using Fuzzy approach [22], [23]-[25]. The proposed controller is simulated for a multi-area power system. Results of simulation show that the fuzzy controllers assure the study overall performance

\section{SYSTEM MODEL}

In general frequency-domain related power balance equation for small-order linearized system LFC representation for the use in frequency control synthesis and analysis is given by [7], [8]:

$$
\Delta P_{T}(s)-\Delta P_{L}(s)=2 H . s . \Delta f(s)+D . \Delta f(s)
$$

The modified multi area block diagram considering demand response(DR) to thermal power system for load frequency control, with communication delay latency is shown [18]. Since spinning reserve in magnitude is performed using DR and with power flow direction, i.e., once deviation in frequency becomes negative (positive), it is required to turn $\mathrm{OFF}(\mathrm{ON})$ a part of the receptive loads for ancillary services (i.e., DR), Equation (1) can be modified as Equation (2):

$$
\Delta P_{T}(s)-\Delta P_{L}(s)+\Delta P_{D R}=2 H . s . \Delta f(s)+D . \Delta f(s)
$$

The power intake repute of controllable loads may be changed immediately by the command sign they acquire [26], [27]. In contrast to the same old spinning reserve-issuer power plants, there's no ramp up and down obstacles on the DR sources. The multi area power system with dynamic demand response load disturbance is shown in Figure 1.

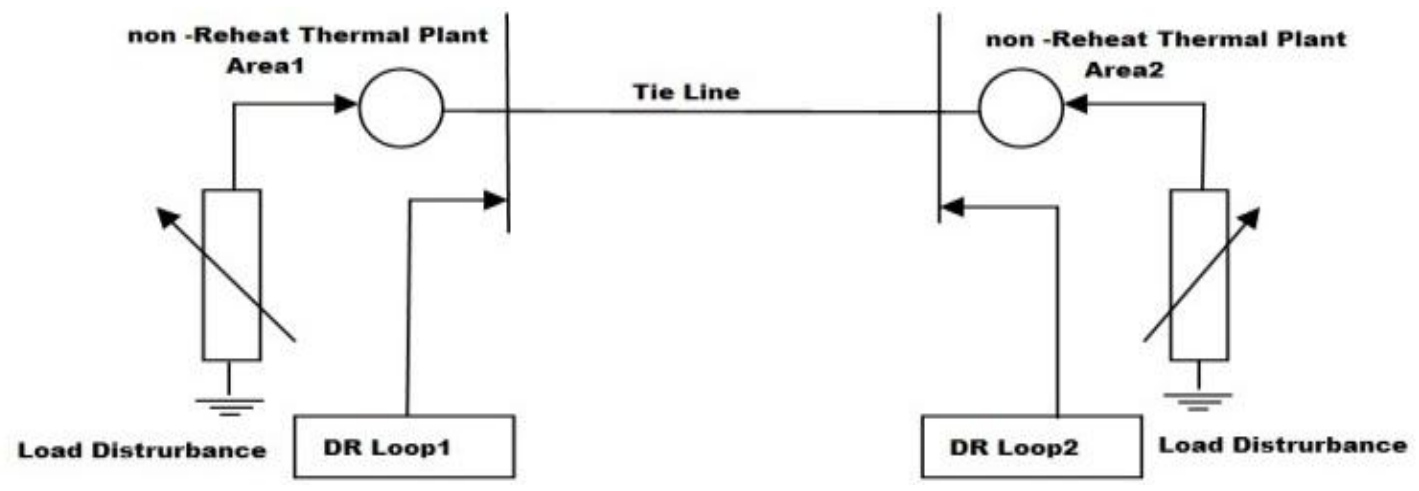

Figure 1. Two-area interconnected power system including Demand response (DR) control loop

The power balance equation for the two-area power system includes Area Control Error (ACE) can be written as Equations (3) \& (4):

$$
\begin{aligned}
& \text { Area1: } A C E(s)=\Delta P_{\text {tiel }}(s)+\beta_{1} \Delta f_{1}(s) \\
& \text { Area2: } A C E_{2}(s)=\Delta P_{\text {tie } 2}(s)+\beta \Delta f_{2}(s)
\end{aligned}
$$

Therefore; the one primary problem for DR is communication delay, known as latency, affects the dynamic performance of the system.

\subsection{State- space dynamical model for LFC-DR for two-area power system}

Representing the LFC model in State space is one of the robust control theories. Now including the dynamic model DR with its latency to the traditional LFC model, modified matrix had obtained considering all non-linearities. The state-space realization of a two-area power system model with a non-reheat steam turbine and DR is given by Equations (5) and (6):

$$
\dot{X}(t)=\mathrm{A} \cdot x(t)+\mathrm{B} \cdot u(t)+\Gamma \cdot w(t)
$$




$$
y(t)=C \cdot x(t)
$$

Where: $A$ - System matrix, $B$-control input matrix, $\Gamma$ - Disturbance matrix, $X$ - State vector, $U(t)$ - input vector, $Y$ - System output which are $\Delta f_{I}(s)$ and $\Delta f_{2}(s)$

\subsection{Padé approximation}

There are various methods and techniques for the linearization of Time delays. From which one of the widely used approximation is "Padé approximation" with delivers strong and successive convergent results [22]. Padé approximations are the most frequently used methods which approximate using rational function. It basically approximates time delays by a quotient of polynomials. Classical control system theory provides the basic relation, but approximation with equal numerator and denominator degree are most broadly advised as shown in Equations (7)-(10).

The Padé function for the time delay functions

$$
e^{-s T_{d}} \approx R_{m n}\left(-s \cdot T_{d}\right)
$$

It is as follows:

$$
R_{m n}\left(-s . T_{d}\right)=P_{m}\left(e^{-s T_{d}}\right) / Q_{n}\left(e^{-s T_{d}}\right)
$$

Where

$$
\begin{aligned}
& P_{m}\left(e^{-s T_{d}}\right)=\sum_{k=0}^{m} \frac{(m+n-k) ! m !}{(m+n) ! k !(m-k) !}\left(-s \cdot T_{d}\right)^{k} \\
& Q_{n}\left(e^{-s T_{d}}\right)=\sum_{k=0}^{n} \frac{(m+n-k) ! n !}{(m+n) ! k !(n-k) !}\left(-s \cdot T_{d}\right)^{k}
\end{aligned}
$$

From above ' $\mathrm{P}$ ' and ' $\mathrm{Q}$ ' are the polynomials of order ' $\mathrm{m}$ ' and ' $\mathrm{n}$ ', respectively. The order usually varies between 1 and 10 . The Padé approximation with 5th-order is recommended and used for the study, since the cut-off frequency usually less than $15 \mathrm{rad} / \mathrm{sec}$. Simulation studies are carried over different values of communication delay latencies $\left(T_{d}\right)$ and the proposed method shows the effective and robust dynamic performance.

\section{RESEARCH MENTOD}

\subsection{Linear quadratic regulator $(\mathrm{LQR})$}

Numerous different classical and modern control theories have been utilized for the LFC problem. In this section, a general controller design(LQR) approach for the LFC problem with the DR control loop is presented. The theory of optimal control is concerned with operating a dynamic system at minimum cost, where the system dynamics are described by a set of linear differential equations and the cost is described by a quadratic function is called the LQ problem. The solution is provided by the Linear-Quadratic Regulator (LQR). Optimal control in state space is centered around the Riccati Equation (11) with state variable functions that must be solved to yield the control law or trajectory.

The simplified version of the LFC-DR with LQR problem is to design controller such that the performance index is minimized for the system given in

$$
\mathfrak{J}=\int_{0}^{\infty}\left[X^{T} \cdot Q \cdot X+\rho \cdot u^{T} \cdot R \cdot u\right] \cdot d t
$$

Where $\rho$ is the weighting factor chosen by the designer, $Q$ is an $n-b y-n$ semidefinite symmetric state cost matrix is an m-by-m positive definite symmetric control cost matrix. With the modified state space Equation (12), ensuring the system matrix is controllable. The implementation of LQR method with required state and control matrices. 


$$
\begin{aligned}
& {\left[\begin{array}{l}
\dot{X} \\
x 1
\end{array}\right]=\left[\begin{array}{ll}
\mathrm{A} & 0 \\
C & 0
\end{array}\right] \cdot\left[\begin{array}{l}
X \\
x 1
\end{array}\right]+\left[\begin{array}{c}
\hat{\mathrm{B}} \\
0
\end{array}\right] \cdot \hat{u}+\left[\begin{array}{c}
\Gamma \\
0
\end{array}\right] \cdot w} \\
& y=\left[\begin{array}{ll}
C & 0
\end{array}\right] \cdot\left[\begin{array}{l}
X \\
x 1
\end{array}\right]
\end{aligned}
$$

\subsection{Fuzzy logic controllers}

Fuzzy logic controllers are rule-based systems that are useful inside the context of complex unwelldescribed methods, especially those which may be controlled by means of a professional human operator without the understanding in their underlying dynamics [18], [28]-[30]. The critical part of the FLC device is a fixed of fuzzy control regulations (FCRs) associated by way of a fuzzy implication and the compositional rule of inference. Since power system dynamic traits are complicated and variable, traditional manipulate techniques can't offer preferred results. Wise controllers can be replaced with conventional controllers to get speedy and accurate dynamic reaction in load frequency control problems. If the device robustness and reliability are greater critical, fuzzy common-sense controllers may be greater useful in solving a huge range of manage issues since traditional controllers are slower and much less green in nonlinear system programs. Fuzzy logic controller is designed to limit fluctuation on device outputs. FLC is designed to cast off the want for non-stop operator attention and used routinely to alter a few variables the manner variable is stored at the reference price. The simple configuration of a fuzzy-common sense control is composed of four principle additives: a fuzzification, an information base, an inference engine, and defuzzification. The fuzzifier maps the enter crisp values into fuzzy variables the use of normalized membership functions and enter profits. The fuzzy logic inference engine then infers the right control motion primarily based at the available rule-base. The fuzzy manage action is translated to the proper crisp cost via the defuzzifier the usage of normalized membership functions and output gains. The block diagram of a fuzzy logic system is shown Figure 2.

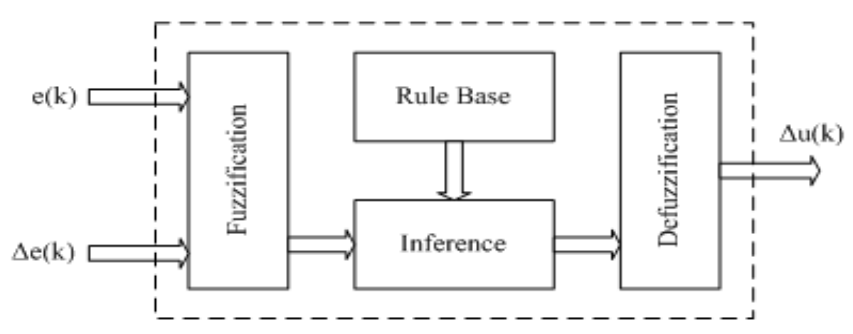

Figure 2. Block diagram representation of a fuzzy logic system

The two normalized input variables, error e and change in error $\Delta \mathrm{e}$ are inputs of FLC, are first fuzzified by T1 fuzzy sets. Two inputs signals are converted to fuzzy numbers first in fuzzifier using three Triangular membership functions, named as Positive Big (B), Positive Small (S), and Zero (Z)). Finally, resultant fuzzy subsets representing the controller output are converted to the crisp values using the Central Of Area (COA) defuzzifier scheme. The rules for the controller design are shown in the Table II are applied and the robust performance for the proposed model can be achieved.

\section{ANALYTICAL APPROACH FOR THE MODEL}

The state equations of conventional load frequency control are well documented [1], [4]. However, the DR control loop is added to the LFC problem in this study. Investigations are done earlier on the impact of the DR control loop on the stability analysis and steady-state error of the given power system. Rewriting the Equation (2), the system frequency deviation can be expressed as follows:

$$
\Delta f(\mathrm{~s})=(2 H . s+D)^{-1}\left[\Delta P_{T}(s)+\Delta P_{L}(s)+G(s) . \Delta P_{D R}\right]
$$

Where

$$
\Delta \mathrm{P}_{\mathrm{T}}(\mathrm{s})=H(s)\left[\Delta P_{s}(s)-\frac{1}{R} \Delta f(s)\right]
$$




$$
\begin{aligned}
& \mathrm{H}(\mathrm{s})=\frac{1}{\left(1+s T_{t}\right)\left(1+s T_{g}\right)} \\
& \mathrm{G}(\mathrm{s})=\frac{-s^{5}+\frac{30}{T_{d}} \cdot s^{4}-\frac{420}{T_{d}^{2}} \cdot s^{3}+\frac{3360}{T_{d}^{3}} \cdot s^{2}-\frac{15120}{T_{d}^{4}} \cdot s+\frac{30240}{T_{d}^{5}}}{s^{5}+\frac{30}{T_{d}} \cdot s^{4}+\frac{420}{T_{d}^{2}} \cdot s^{3}+\frac{3360}{T_{d}^{3}} \cdot s^{2}+\frac{15120}{T_{d}^{4}} \cdot s+\frac{30240}{T_{d}^{5}}}
\end{aligned}
$$

Based on the final value theorem, the steady state value of the frequency deviation can be obtained as follows [14]:

$$
\Delta f_{\mathrm{ss}}=\frac{\Delta P_{s, s s}+\Delta P_{D R, s s}-\Delta P_{L}}{D+\frac{1}{R}}
$$

From the above Equation (17); the following conclusions can be made for the analysis of the model:

a. As the frequency deviation will not be zero unless the supplementary and/or DR controls exist.

b. With the availability of DR in the LFC, a higher reliability of frequency regulation can be achieved, since the DR control loop can complement the supplementary control loop. In cases when the supplementary control is not available, if enough DR resources are available, the performance of the frequency regulation can be guaranteed by the DR loop.

c. To have zero frequency deviation at steady-state, the required control effort can be split between the supplementary and DR control loops. In other words, an ISO/RTO will have the opportunity to perform the regulation services in a cost-effective way and analyze the frequency response of the system quickly. This goal can be achieved only in the proposed formulation [20] with an added control loop for DR.

Therefore, taking above conclusions into consideration: With DR availability in the LFC, the required control effort can be splitted in to two control loops based on their cost at real -time electricity market

$$
\begin{aligned}
& \Delta P_{S}(s)=\alpha . \text { control effort } \\
& \Delta P_{D R}(s)=(1-\alpha) . \text { control effort }
\end{aligned}
$$

And finally based on the control effort the supplementary and DR control loop of the system is modified and governed by the below equation:

$$
(1-\alpha) G(s)+\alpha \cdot H(s)
$$

where $0<\alpha<1$ is the share of traditional regulation services in the required control effort. It shows that if $\alpha=1$, the total regulation is provided by traditional regulation services and if $\alpha=0$ i.e. for this time the total control would be provided by DR. The decision of $\alpha$ should be made by ISO/RTO, based on the price of DR and Traditional regulatory services in the real-time market explored by authors [22]. Simulation studies are carried on the system frequency deviation considering two different values of $\alpha$.

a. If $\alpha=0.1,10 \%$ of the regulation id provided by the supplementary control and $90 \%$ from DR

b. If $\alpha=0.8,80 \%$ of the regulation id provided by the supplementary control and $20 \%$ from DR

In the next section, simulation results for the LFC-DR model of a single- area power system are presented to verify the effectiveness of the proposed model compared to that classic controller.

\section{SIMULATION RESULTS}

The result of several different simulation studies in this section provides an important feature of the proposed LFC-DR model. The parameters used in the simulation studies are given in Appendix Table for two different operating points. Using, the load disturbance, as the system input. It can be noticed from this table that a higher share of control effort for the DR control loop, i.e., smaller $\alpha$, will provide a higher gain and phase margin, indicating a more stable system. 


\subsection{Case 1}

In the first simulation study, a 0.1 pu load disturbance (with $10 \%$ Load perturbation) was applied to the two-area LFC-DR power system model with the parameters in Appendix Table Using proposed method, the frequency deviations is quickly driven back to zero and the controller designed using PID controller has the best performance in control and damping of frequency. Frequency deviation for LFC-DR models with different control effort for a Two area power system are shown in Figure 3.

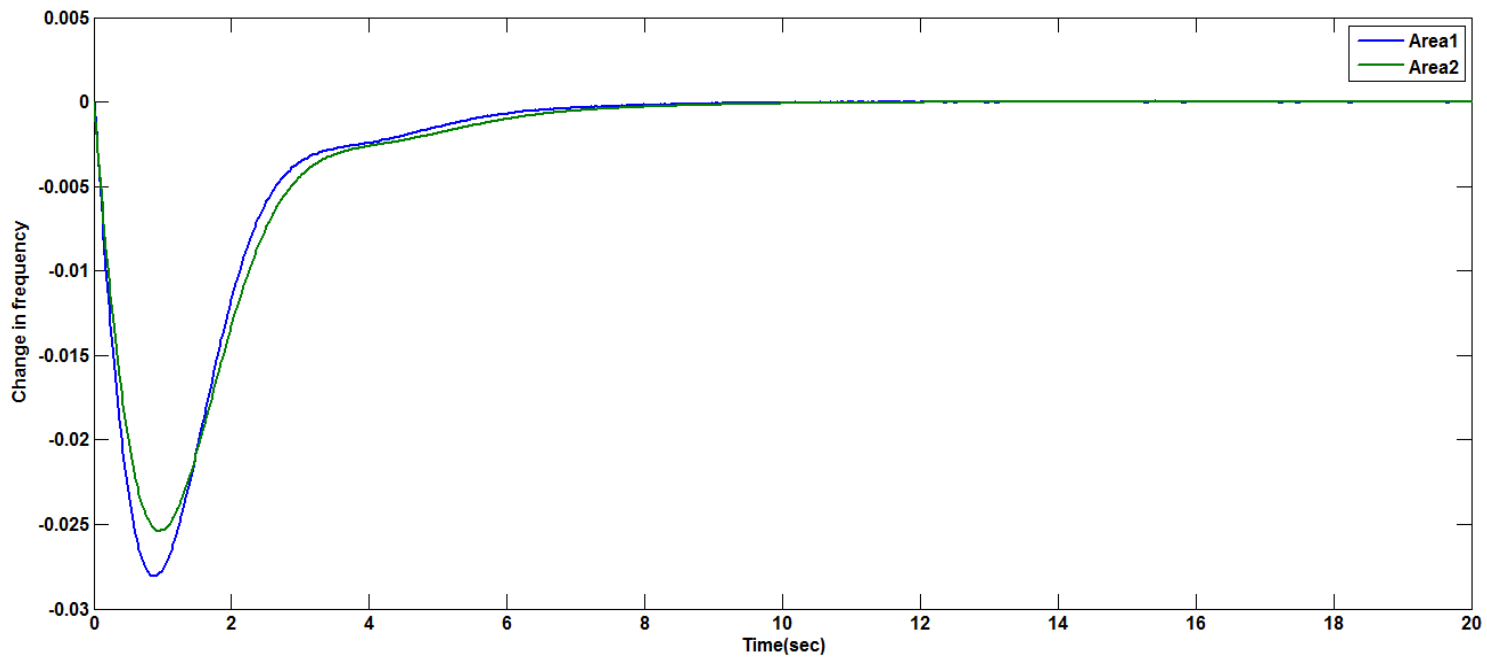

(a)

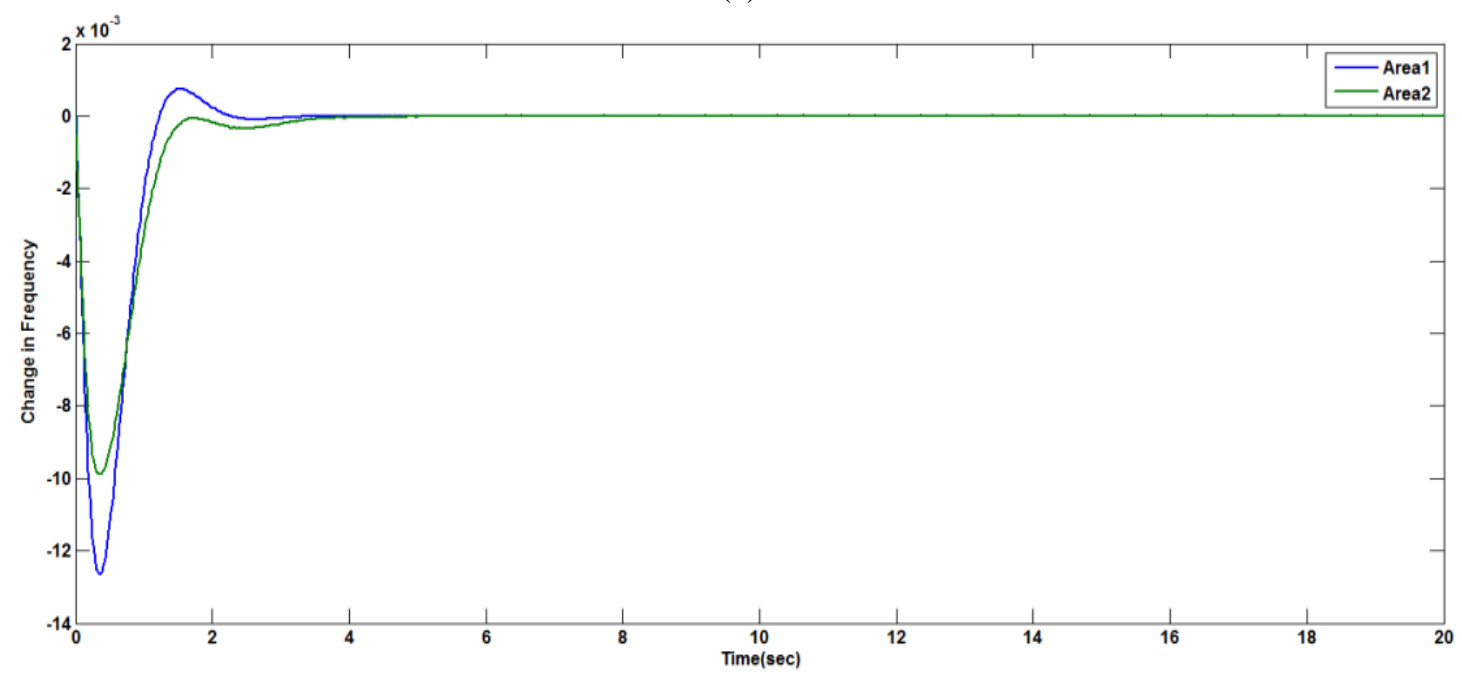

(b)

Figure 3. Frequency deviation for LFC-DR model with conventional PID controller (a) control effort 0.1

(b) control effort 0.8

\subsection{Case 2}

In the second simulation study, a 0.1 p.u. load disturbance was applied to the two-area LFC -DR model with the parameters shown in Appendix table. Using proposed method, the frequency deviations are driven back to zero and the controller designed using Fuzzy-PID controller has the good performance in control and damping of frequency with different control efforts. This proposed LFC-DR model has a superior performance over the conventional LFC during the transient period considering the both cases of control effort i.e. alpha values (DR participation). Frequency deviation for LFC-DR models (with Fuzzy-PID controller) with $\alpha$ values are shown in Figure 4. 


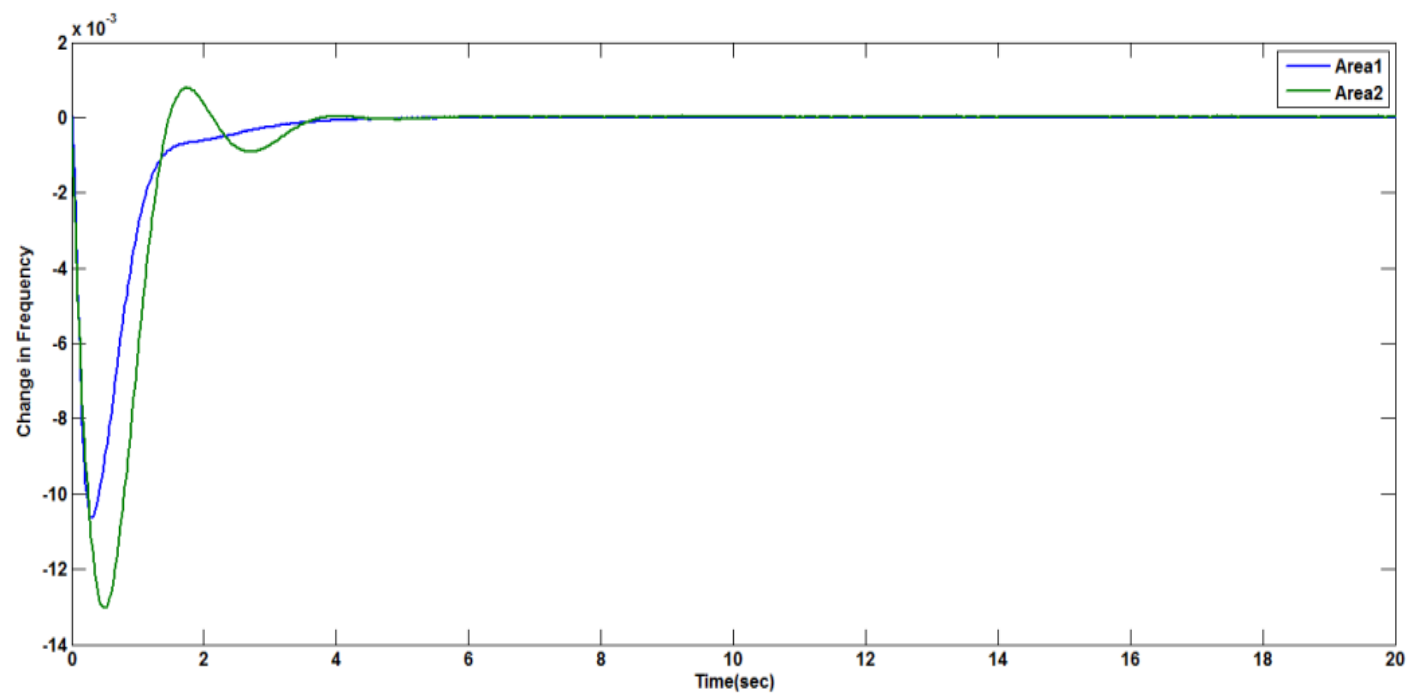

(a)

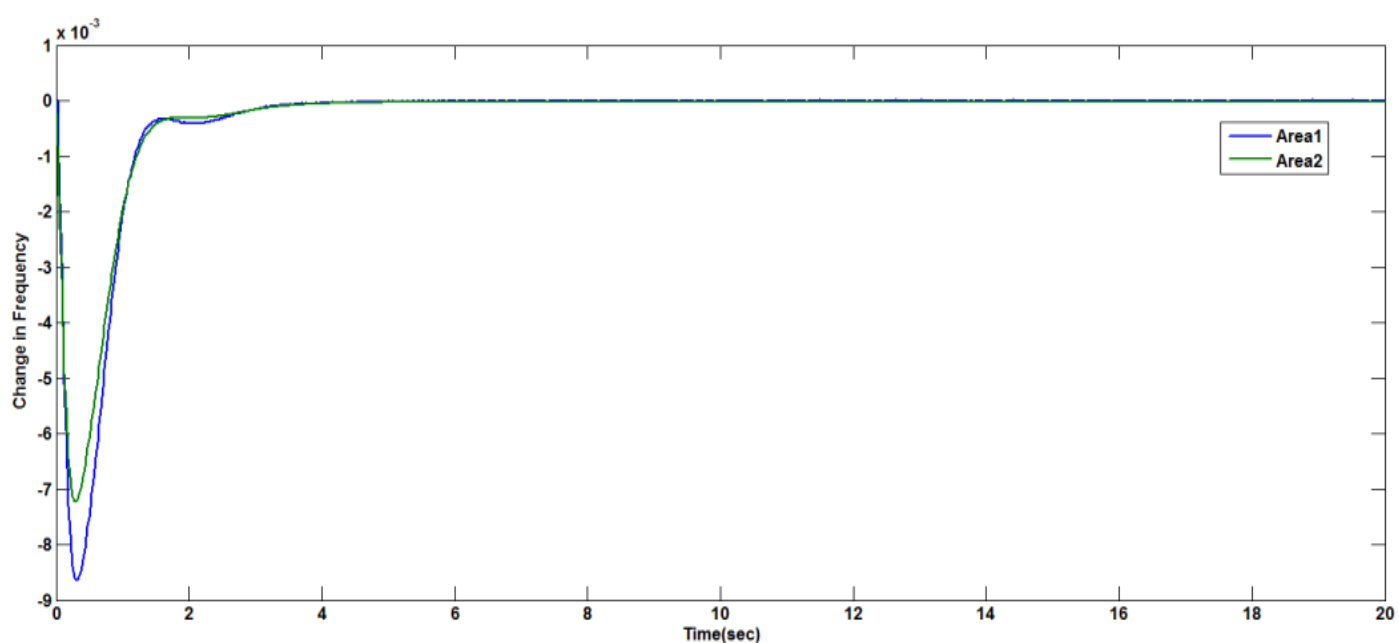

(b)

Figure 4. Frequency deviation for LFC-DR model with Fuzzy-PID controller (a) control effort 0.1 (b) control effort 0.8

\subsection{Case 3}

In this simulation study, a 0.1 pu load disturbance was applied to the two-area LFC -DR model with the parameters shown in Appendix. Using proposed method, the frequency deviations is quickly driven back to zero and the controller designed using LQR-Fuzzy controller has the robust and superior performance in control and damping of frequency when compared with conventional PID Controllers, Considering the both cases of control effort i.e alpha values (DR participation). Frequency deviation for LFC-DR models (with LQR-Fuzzy controller) with $\alpha$ value are shown in Figure 5.

For hree cases based on the settling time and Undershoot for all the models i.e. LFC-DR with PID controllers and the two-proposed approach (Fuzzy-PID and LQR-Fuzzy) the analysis is carried. From the analysis best system dynamic performance is achieved by the proposed LQR-Fuzzy approach. The proposed method shows the dynamic and robust response for this dynamic demand response LFC model. Comparisons are made with different controllers and with different control efforts for the model. The Figure 6 and Figure 7 show different comparative analysis. 


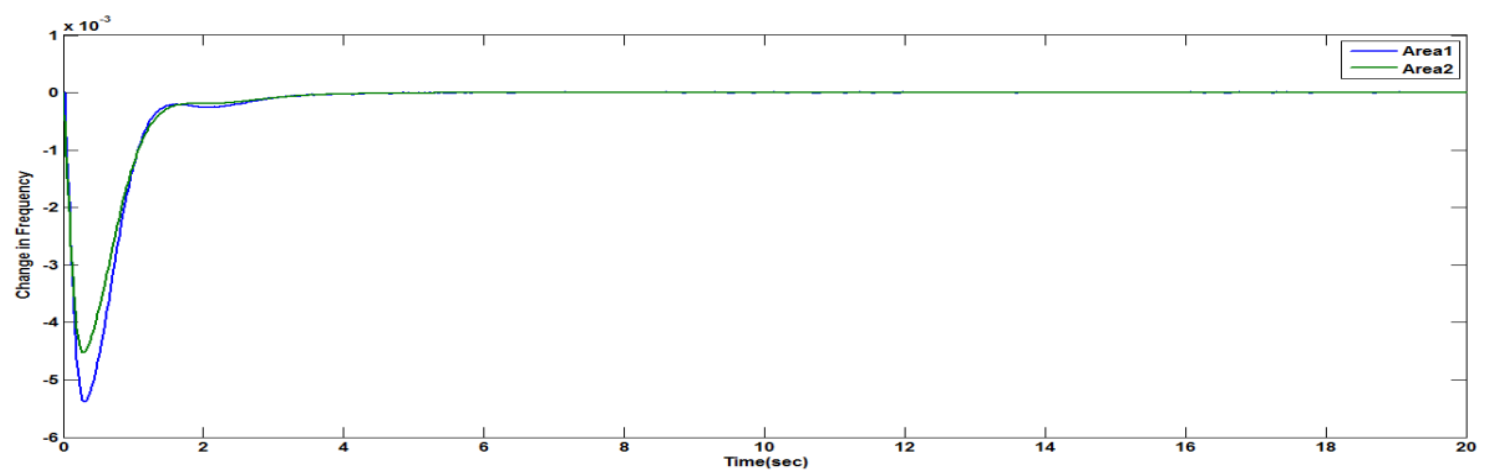

(a)

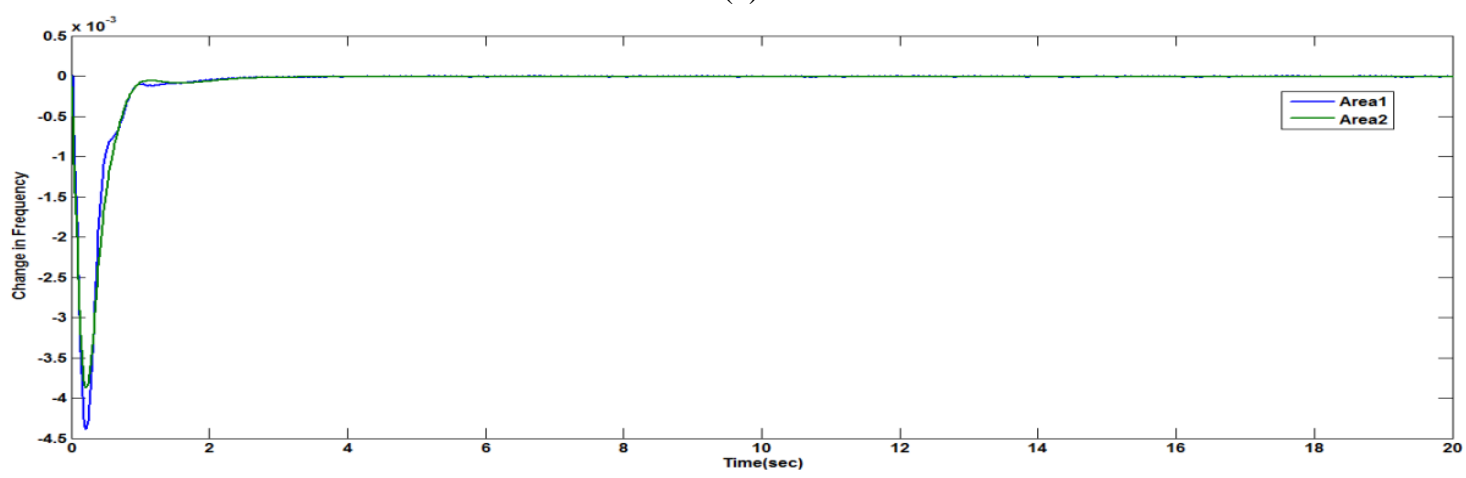

(b)

Figure 5. Frequency deviation for LFC-DR model with LQR-Fuzzy controller (a) control effort 0.1 (b) control effort 0.8

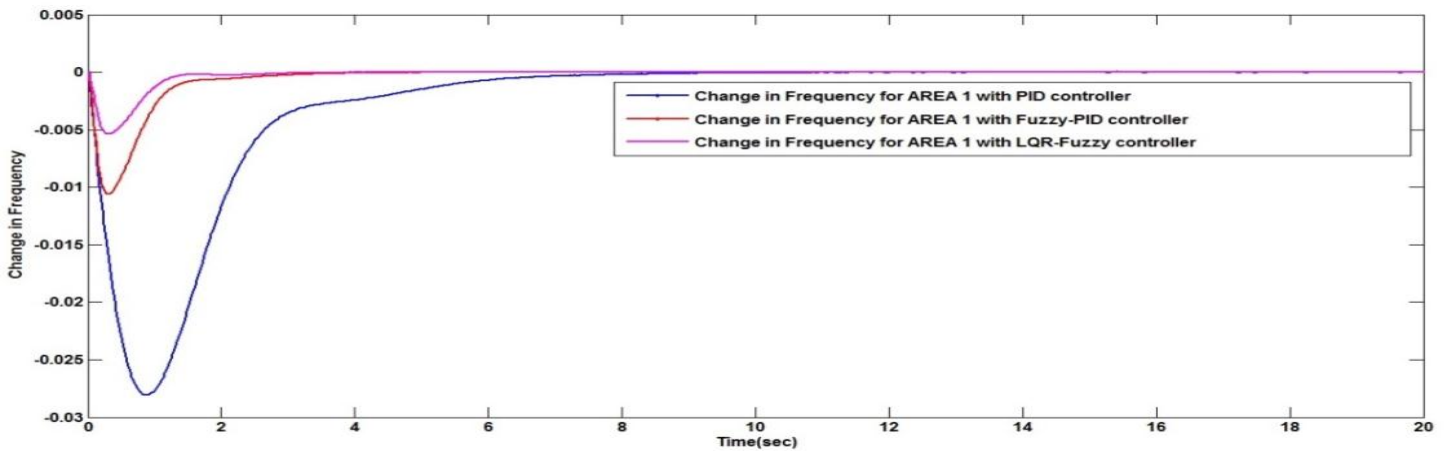

(a)

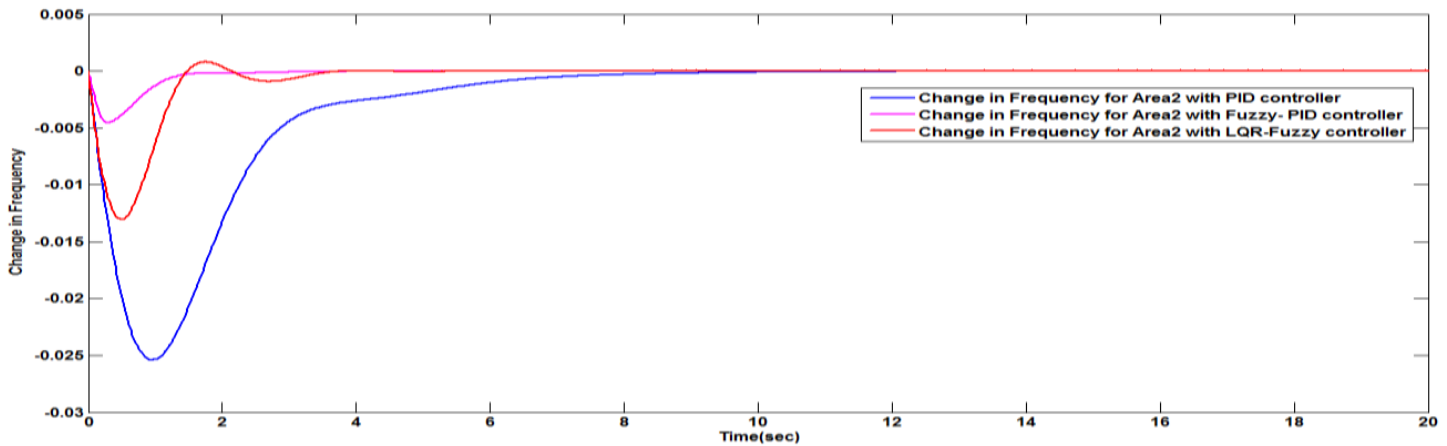

(b)

Figure 6. Frequency deviation for LFC-DR model with different controller with control effort 0.1 (a) Area1 (b) Area2 


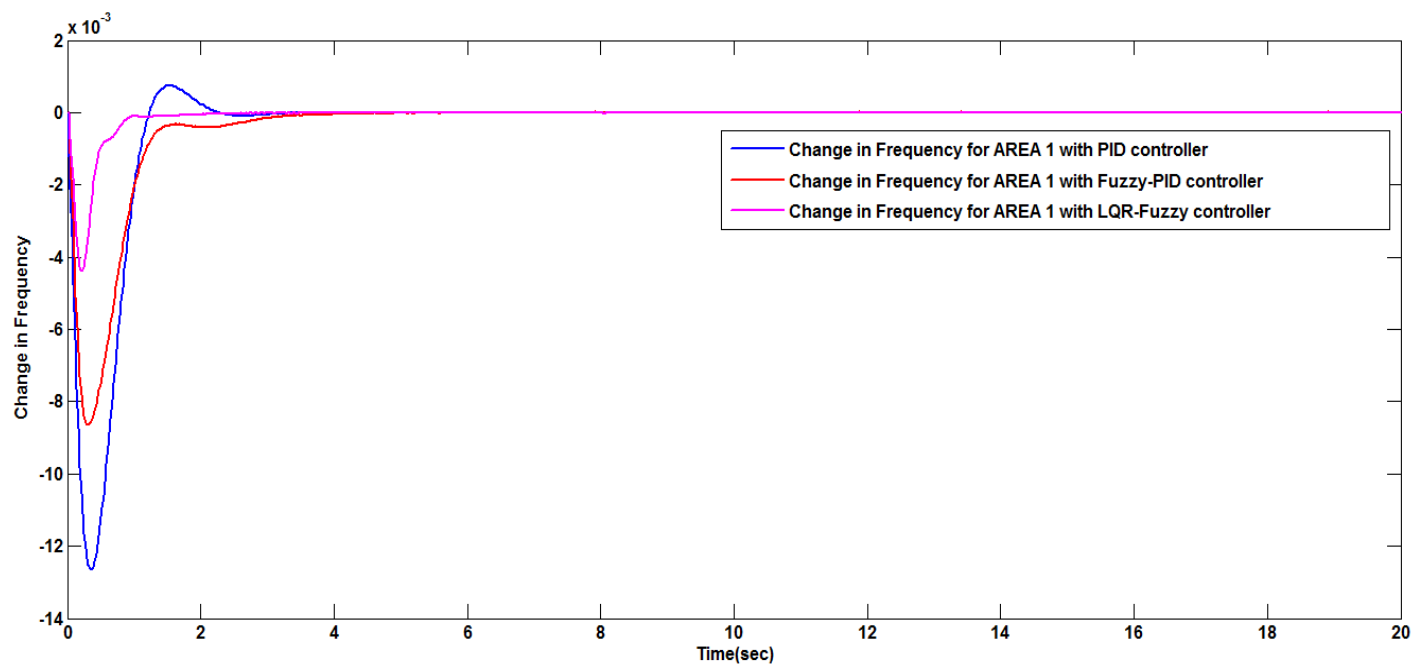

(a)

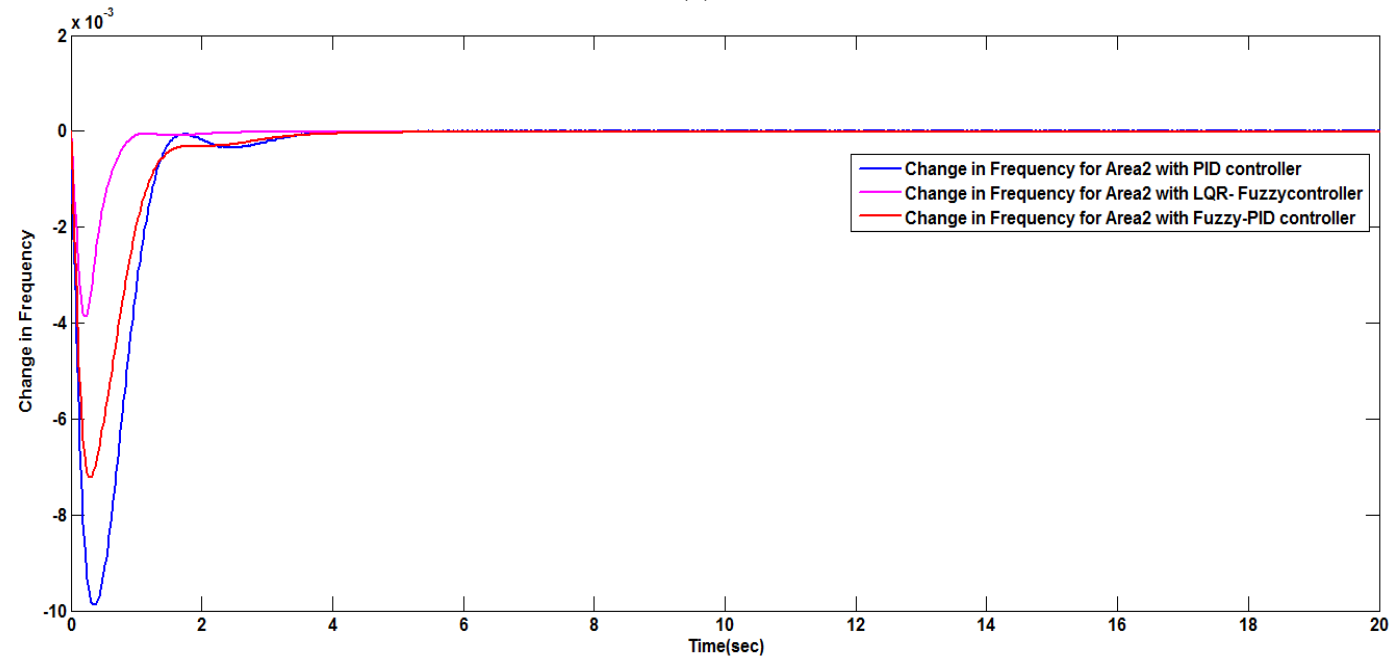

(b)

Figure 7. Frequency deviation for LFC-DR model with different controller with control effort 0.8 (a) Area 1 (b) Area 2

Another significant feature of the LFC-DR model is to evaluate the impact of communication delay of the DR control loop on the system performance for frequency stabilization. To show robustness of the proposed controller on impact of latency, a simulation study was performed on LFC-DR with communication delay latency $\mathrm{T}_{\mathrm{d}}=0.1$ with control effort share of $\alpha=0.1$ and $\alpha=0.8$ with different controller as shown in Figure 8. 


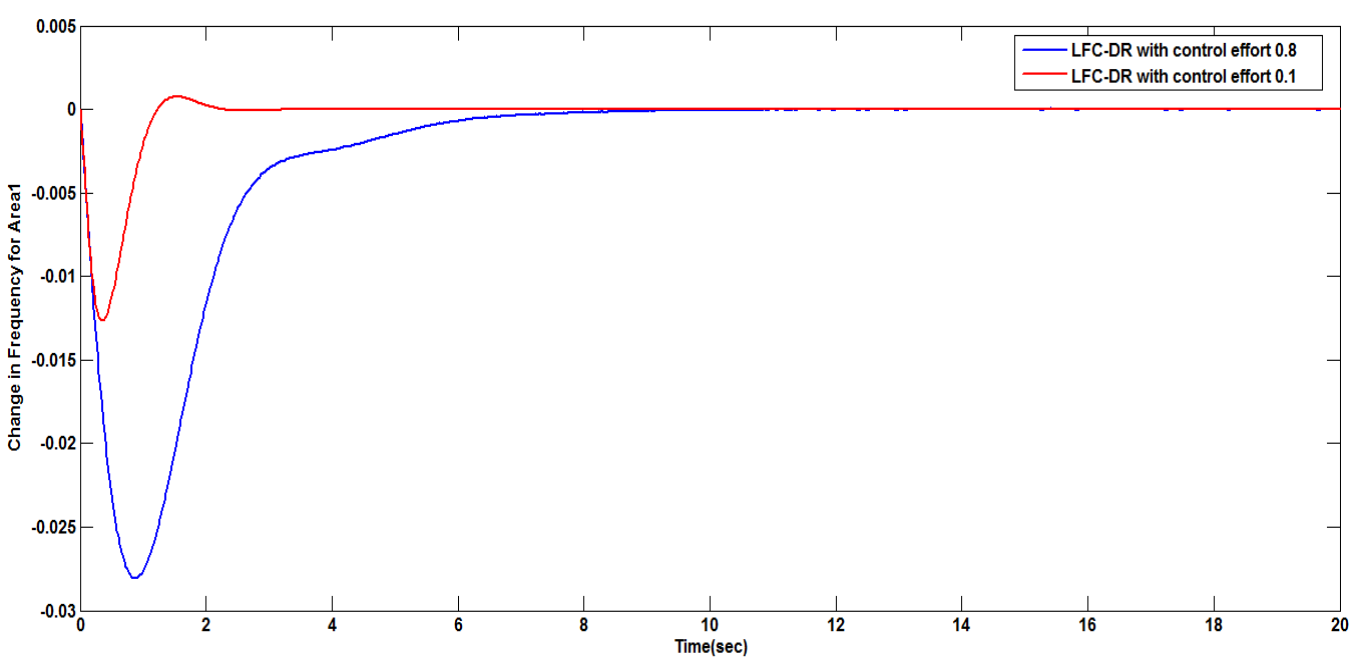

(a)

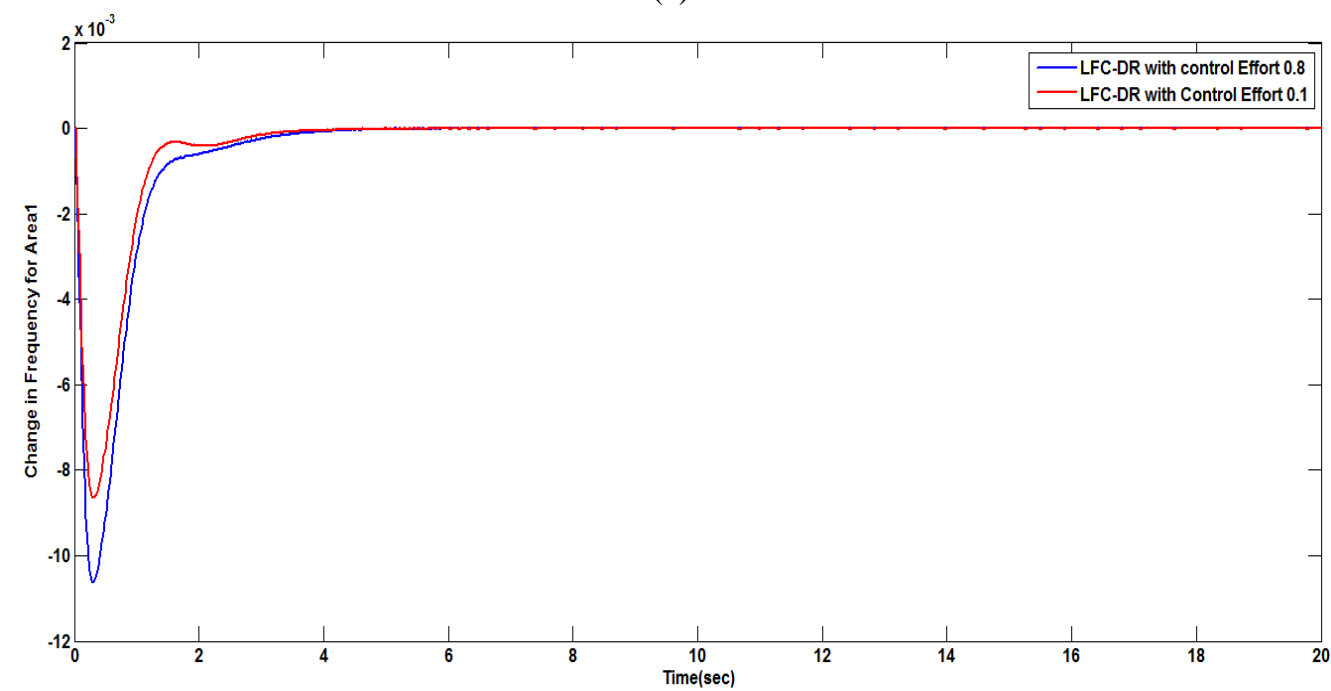

(b)

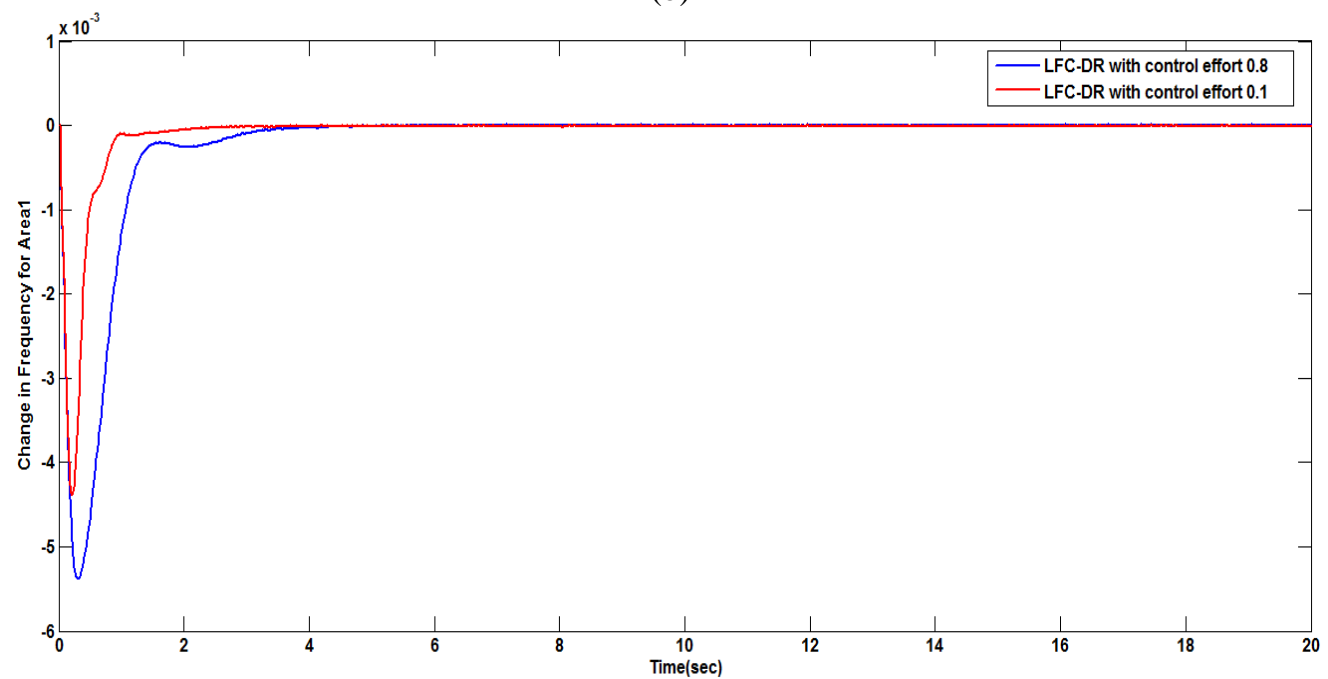

(c)

Figure 8. Frequency deviation for LFC-DR model with different controllers with control effort 0.1 and 0.8 (a) PID controller (b) Fuzzy-PID controller (c) LQR-Fuzzy Controller 
From the simulation studies, it is seen that the proposed method also best for the different communication latencies when compared to the conventional controllers for LFC-DR model.

\section{CONCLUSION}

In this paper a new method for load frequency control with DR loop using LQR-Fuzzy and FuzzyPID controller for a two-area power system has been proposed. The proposed method was applied to twoarea non-reheat thermal power system for two different control effort $(\alpha)$ operating conditions. Simulation results obtained from the designed controller guarantees the robust stability and robust performance of the system. To demonstrate the robustness in the performance of the proposed method, settling time, and undershoot of the response of the system are being considered. Also, the simulation results show that the proposed method is robust to change in the parameter of the system and has good performance as compared to that of LFC-DR classical with controller in all the operation condition. In general, there exist large power systems of multi-area where different Gencos and Lagcos are available in each area. In future work, the application can be extended to LFC-DR in Hydro-Thermal power systems and by considering the effect of different latencies.

\section{REFERENCES}

[1] http://eetd.lbl.gov/ea/ems/reports/congress-1252d.pdf Accessed June 2009

[2] http://www.ferc.gov/legal/staff-reports/demand-response.pdf, a report to U.S. Congress, "Federal Energy Regulatory Commission", 2008.

[3] C. Concordia and L. Kirchmayer, "Tie-line power and Frequency Control of Electric Power Systems," Power Apparatus and Systems, Part III. Transactions of the American Institute of Electrical Engineers, vol. 72, no. 2, pp. 562-572, 1953.

[4] G. Quazza, "Noninteracting controls of interconnected Electric Power Systems," Power Apparatus and Systems, IEEE Transactions on, no.7, pp. 727-741, 1966.

[5] I. Vajk, L. Keviczky, J. Hetthessy, and K. Kovacs, "Adaptive load frequency control of the Hungarian power system," Automatica, vol. 21, no. 2, pp. 129-137, 1985.

[6] Vaibhav Donde, M. A. Pai, and Ian A. Hiskens, "Simulation and Optimization of AGC after Deregulation," IEEE Trans. on Power Systems, vol. 16, no. 3, 2001.

[7] H. Bevrani, Robust Power System Frequency Control. New York, NY, USA: Springer, ch. 1-3(2009).

[8] P. Kundur, Power system Stability and Control. New York, NY, USA: McGraw-Hill, ch. 11(1994).

[9] R. Doherty and M. O'Malley, "A new approach to quantify reserve demand in systems with significant installed wind capacity," IEEE Trans. Power Syst., vol. 20, no. 2, pp. 587-595, May 2005.

[10] http://energy.gov/oe/technology-development/smart-grid, accessed U.S. Department of Energy, Smart Grid, Sep. 2013.

[11] D. Jay and K. S. Swarup, "Frequency restoration using dynamic demand control under smart grid environment," in Proc. IEEE PES Innovative Smart Grid Technologies, India (ISGT India), Kerala, pp. 311-315, 2011.

[12] S. A. Pourmousavi and M. H. Nehrir, "Demand response for smart microgrid: Initial results," in Proc. 2nd IEEE PES Innov. Smart Grid Technol. (ISGT), Anaheim, CA, USA, pp. 1-6, 2011.

[13] S. A. Pourmousavi, M. H. Nehrir, and C. Sastry, "Providing ancillary services through demand response with minimum load manipulation," in Proc. 43rd North Amer. Power Symp. (NAPS), Boston, MA, USA, pp. 1-6, 2011.

[14] Ibraheem, D. P. Kothari, "Recent philosophies of automatic generation control strategies in power systems," IEEE Trans. Power Syst., vol. 20, pp. 346-357, 2005.

[15] Karnavas YL, Papadopoulos DP. "AGC for autonomous power system using combined intelligent techniques," Electr Power Syst Res, vol. 62, pp. 225-39, 2002.

[16] Indulkar CS, Raj B. "Application of fuzzy controller to automatic generation control," Electr Mach Power Syst, vol. 23, pp. 209-20, 1995 .

[17] Chown GA, Hartman RC. "Design and experiment with a fuzzy controller for automatic generation control (AGC)," IEEE Trans Power Syst, 1998, vol. 13, pp. 965-70.

[18] P.Srividya Devi, Dr. R Vijaya Santhi, Dr. D.V.Pushpalatha, "Introducing LQR-Fuzzy Technique with Dynamic Demand ResponseControl Loop to Load Frequency Control Model," International Federation of Automatic control (IFAC-Eleseveir), vol. 49, no. 1, pp. 567-572, 2016.

[19] K.R. Sudha, R. VijayaSanthi, "Robust Decentralized Load Frequency Control of Interconnected Power System with Generation Rate Constraint using Type-2 Fuzzy approach," Int. Jrn. of Electr. Power and Energy Systems, vol. 33, pp. 699-707, 2011.

[20] S. Ali Pourmousavi,M. H. Nehrir, "Introducing Dynamic Demand Response in the LFC Model," IEEE Trans. Power Syst., vol. 29, no. 4, pp. 1562-1572, June 2014.

[21] S. A. Pourmousavi and M. H. Nehrir, "Real-time central demand response for primary frequency regulation in microgrids," IEEE Trans. Smart Grid, vol. 3, no. 4, pp. 1988-1996, Dec 2012.

[22] R. C. Dorf and R. H. Bishop, Modern Control Systems, 7th ed. New York, NY, USA: Addison-Wesley, p. 807(1995). 
[23] T. Hiyama, "Design of decentralized load-frequency regulators for interconnected power systems," Proc. IEE Generation, Transmission, Distribution Conf., vol. 129, no. 1, pp. 17-23, 1982.

[24] K.R. Sudha, R.VijayaSanthi "Load Frequency Control of an Interconnected Reheat Thermal system using Type-2 fuzzy system including SMES units”, International Journal of Electrical Power and Energy Systems, vol. 43, pp. 1383-1392, (2012).

[25] R. VijayaSanthi, K.R. Sudha, Prameela Devi S, "Robust Load Frequency Control of multi-area interconnected system including SMES units using Type-2 Fuzzy controller," International conference on Fuzzy Systems, July 2013.

[26] A. J. Lampiao, "Control of an Autonomous Hybrid Microgrid as Energy Source for a Small Rural Village," International Journal of Electrical and Computer Engineering (IJECE), vol. 7, 2017.

[27] Phuong Hoang Vu, Ngoc Dinh, Nam Hoang, Quan Nguyen, Dich Nguyen, Minh Tran, "A Generalized Parameters Tuning Method of PR Controllers for Dynamic Voltage Restorers," International Journal of Power Electronics and Drive Systems (IJPEDS), vol. 9, no. 4, December 2018.

[28] N. N. Baharudin, S. M. Ayob "Brushless DC Motor Speed Control using Single Input Fuzzy PI Controller," International Journal of Power Electronics and Drive Systems (IJPEDS), vol. 9, no. 4, December 2018.

[29] M.H.H Ichsan, W. Kurniawan and M. Huda, "Water Quality Monitoring with Fuzzy Logic Control Based on Graphical Programming," TELKOMNIKA (Telecommunication, Computing, Electronics and Control), vol. 14, no. 4, pp. 1446-1453, 2016.

[30] G. Muni Reddy, T. Gowri Manohar, "Fuzzy Logic Controller for grid connected Wind Energy Conversion System,” Indonesian Journal of Electrical Engineering, vol. 6 no.1, March 2018.

\section{APPENDICES}

$\mathrm{Tg} 1=\mathrm{Tg} 2=0.08 \mathrm{Sec}, \mathrm{Tt} 1=\mathrm{Tt} 2=0.4 \mathrm{sec}, \mathrm{R} 1=\mathrm{R} 2=3 \mathrm{~Hz} / \mathrm{p} \cdot \mathrm{u}, 2 \mathrm{H} 1=2 \mathrm{H} 2=0.1667$ p.u,D1=D2=0.015 p.u.Td=0.1 sec, $\Delta$ PL1 $=\Delta$ PL2 $=0.1$ p.u

\section{Matrices}

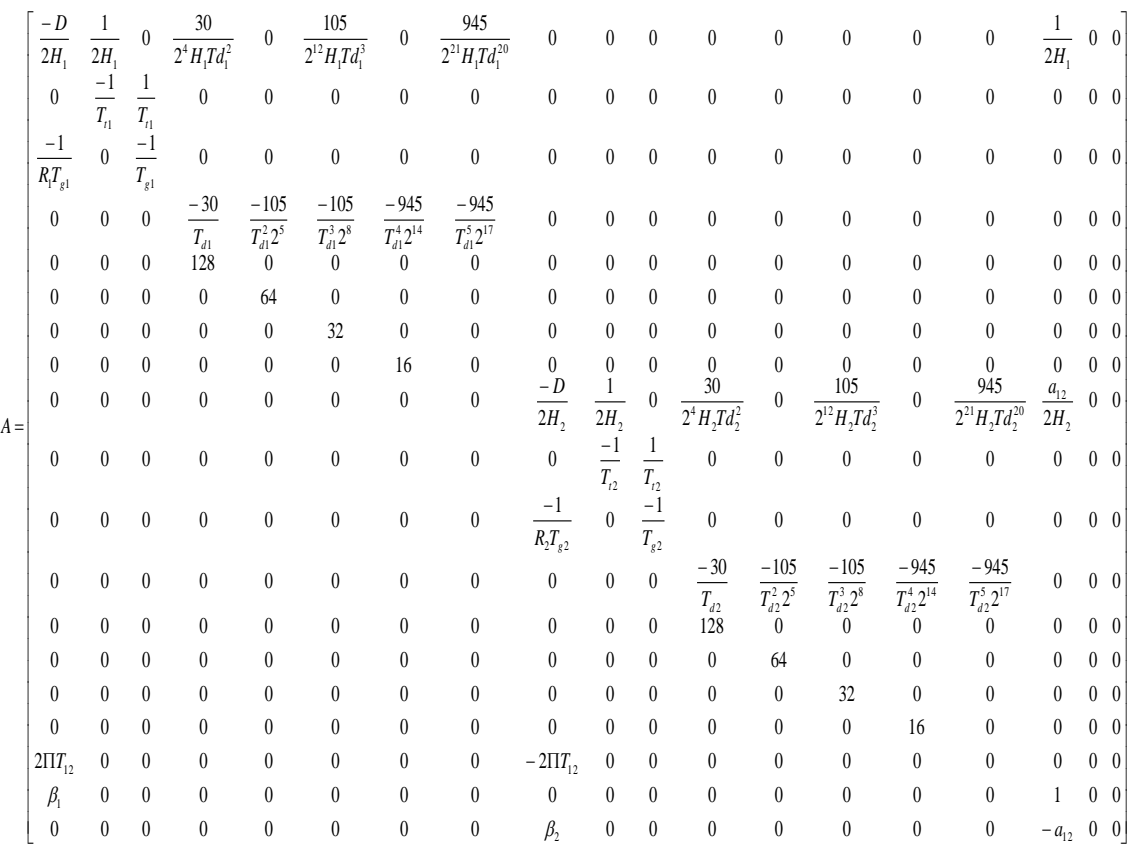

$$
\begin{aligned}
& B=\left[\begin{array}{llllllllllllllllllll}
0 & 0 & 0 & 0 & 0 & 0 & 0 & 0 & \frac{-1}{2 H_{2}} & 0 & 0 & 0 & 0 & 0 & 0 & 0 & 0 & 0 & 0 \\
0 & 0 & 0 & 0 & 0 & 0 & 0 & 0 & 0 & 0 & \frac{1}{T_{g 2}} & 16 & 0 & 0 & 0 & 0 & 0 & 0 & 0 \\
\frac{-1}{2 H_{1}} & 0 & 0 & 0 & 0 & 0 & 0 & 0 & 0 & 0 & 0 & 0 & 0 & 0 & 0 & 0 & 0 & 0 & 0 \\
0 & 0 & \frac{1}{T_{g 1}} & 16 & 0 & 0 & 0 & 0 & 0 & 0 & 0 & 0 & 0 & 0 & 0 & 0 & 0 & 0 & 0
\end{array}\right]^{T} \\
& \Gamma=\left[\begin{array}{ccccccccccccccccccc}
0 & 0 & 0 & 0 & 0 & 0 & 0 & 0 & \frac{-1}{2 H_{2}} & 0 & 0 & 0 & 0 & 0 & 0 & 0 & 0 & 0 & 0 \\
\frac{-1}{2 H_{1}} & 0 & 0 & 0 & 0 & 0 & 0 & 0 & 0 & 0 & 0 & 0 & 0 & 0 & 0 & 0 & 0 & 0 & 0
\end{array}\right]^{T}
\end{aligned}
$$




\section{BIOGRAPHIES OF AUTHORS}
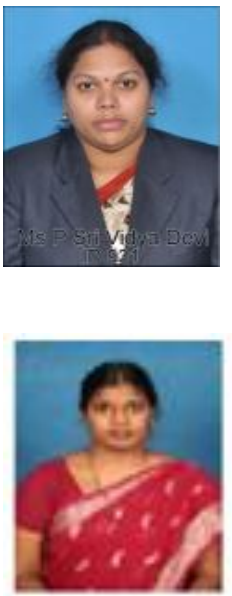

Srividya Devi, presently pursuing her Ph.D in Power Systems from Andhra University. She had done her M.Tech in (Electrical Power Engineering) 2008 from JNT University College of Engineering, Hyderabad. She had overall experience of 10 years in teaching. She had published 9 Research papers in various National Journals and Conferences and attended more the 10 workshops conducted by NMEICT and IITB, IITK etc. She is CLAD (Certified LabVIEW Associate Developer) certified by National Instruments. Her areas of interests are Power Systems, Network Analysis and Fuzzy Systems etc.

E-mail:srividyadevi2001@ gmail.com

R. Vijaya Santhi received her Doctorate in Electrical Engineering in 2014 by Andhra University. She did her M.Tech in Power systems, from JNTU Kakinada in 2008. Presently, she is working as Assistant Professor in the Department of Electrical Engineering, Andhra University, and Visakhapatnam. She has over all 13 years of experience in Teaching. She has published various papers in International Journals like Elsevier and IEEE Transactions and in Reputed Conferences. Her areas of interests are Power Systems, Fuzzy logic Control systems.

Email:rvijayasanthi.ee@auvsp.edu.in 